\title{
Evaluation of the Corrosivity of Dust Deposited on Waste Packages at Yucca Mountain, Nevada
}

\author{
Charles Bryan ${ }^{1}$, Russ Jarek ${ }^{1}$, Tom Wolery ${ }^{2}$, Dave Shields ${ }^{3}$, Mark Sutton $^{2}$, Ernest Hardin ${ }^{3}$, Deborah Barr ${ }^{4}$
}

Small amounts of dust will be deposited on the surfaces of waste packages in drifts at Yucca Mountain during the operational and the preclosure ventilation periods. Salts present in the dust will deliquesce as the waste packages cool and relative humidity in the drifts increases. In this paper, we evaluate the potential for brines formed by dust deliquescence to initiate and sustain localized corrosion that results in failure of the waste package outer barrier and early failure of the waste package. These arguments have been used to show that dust deliquescence-induced localized or crevice corrosion of the waste package outer barrier (Alloy 22) is of low consequence with respect to repository performance.

Measured atmospheric and underground dust compositions are the basis of thermodynamic modeling and experimental studies to evaluate the likelihood of brine formation and persistence, the volume of brines that may form, and the relative corrosivity of the initial deliquescent brines and of brines modified by processes on the waste package surface. In addition, we evaluate several mechanisms that could inhibit or stifle localized corrosion should it initiate.

The dust compositions considered include both tunnel dust samples from Yucca Mountain, National Airfall Deposition Program rainout data, and collected windblown dust samples. Also considered is sublimation of ammonium salts, a process that could affect dust composition prior to deliquescence. Ammonium chlorides, nitrates, and even sulfates sublimate readily into ammonia and acid gasses, and will be lost from the surface of the waste package prior to deliquescence.

Arguments are developed using a logic-tree approach, based upon that presented in Apted et al. (2005, JOM), evaluating the potential importance of localized corrosion by high-temperature deliquescent brines. We expand upon the approach used in those documents, considering a wider range of dust and brine compositions, conditions, and arguments. In order for dust deliquescence to cause failure of the waste package, each of the following propositions must be affirmative:

1) Can multiple-salt deliquescent brines form at elevated temperature? Yes. Some important salt phases in the dust (e.g., ammonium phases) will sublimate prior to deliquescence. However, other salts in the dust are stable, and form eutectic assemblages that can deliquesce at temperatures much higher than the individual salt components. For most single salt phases (nitrates, chlorides, and carbonates) boiling points at one atmosphere are limited to temperatures below $120^{\circ} \mathrm{C}$-boiling points of saturated salt solutions represent the maximum temperature of deliquescence at a given pressure. Multi-salt mixtures always boil at higher temperatures than the individual salt components. The boiling points for important salt assemblages predicted to occur on the waste package surface have been investigated experimentally. The two-salt mixture $\mathrm{NaCl}+\mathrm{KNO}_{3}$ boils at a maximum temperature of $134^{\circ} \mathrm{C}$ and the three-salt mixture, $\mathrm{NaCl}+\mathrm{KNO}_{3}+\mathrm{NaNO}_{3}$, at over $190^{\circ} \mathrm{C}$. By inference, the four-salt mixture, $\mathrm{NaCl}+\mathrm{KNO}_{3}+\mathrm{NaNO}_{3}+\mathrm{Ca}\left(\mathrm{NO}_{3}\right)_{2}$, must also deliquesce at temperatures above $190^{\circ} \mathrm{C}$.

2) If brines form at elevated temperature, will they persist? Sometimes. Brines on the waste package surface will degas acid phases- $\mathrm{HCl}$ and $\mathrm{HNO}_{3}$-which can result in precipitation of less deliquescent salts and dryout. High temperature calcium and magnesium chloride brines degas rapidly and dry out, precipitating non-deliquescent hydroxide-chloride phases. All predicted deliquescent brine compositions are unstable in the drift environment and will degas acid phases, leading to an increase in $\mathrm{pH}$, increases in the $\mathrm{NO}_{3} / \mathrm{Cl}$ ratio, precipitation of less deliquescent salts, and, sufficient degassing occurs, dryout. Reactions with low-solubility minerals in the dust (silicates, sulfates) may also lead to dryout, by modifying cation concentrations in the brine (specifically, divalent cations are removed) and changing the deliquescent salt assemblage. However, for most brines, kinetics of acid degassing and mineral reactions are slow, and dryout is unlikely. 
3) If deliquescent brines persist, are they corrosive? No. Brines that form at elevated temperature by dust deliquescence are near-neutral to alkaline $\mathrm{pH}$, nitrate-rich and chloride-poor, and are benign with respect to initiation of localized corrosion. Based on thermodynamic principles, brines that form beyond the temperature limits of available thermodynamic models are constrained to be even more nitrate-rich, and recent experimental data confirms that nitrate continues to inhibit localized corrosion at temperatures up to $220^{\circ} \mathrm{C}$. Processes occurring after deliquescence, including acid degassing and reactions with silicate minerals, do not result in corrosive brines. Acid degassing has beneficial effects, increasing the $\mathrm{NO}_{3} / \mathrm{Cl}$ ratio of the remaining solution, and even small degrees of degassing will result in increases in the brine $\mathrm{pH}$, to values ranging from near-neutral to alkaline. Brine interactions with silicate minerals may also buffer the $\mathrm{pH}$ to near-neutral or slightly alkaline values, and may lead to dryout by precipitation of a less deliquescent salt assemblage.

4) If deliquescent brines are potentially corrosive, will they initiate localized corrosion? No. Potential dust deposition on waste packages in the drift has been quantified, and brines generated by dust deliquescence will be limited in volume. Physical isolation of salt minerals in the dust may inhibit formation of eutectic brines, further decreasing deliquescent brine volumes. Capillary and surface tension effects in the dust are likely to reduce surface contact or inhibit brine flow into pores or crevices. Characterization of dust porosity indicates that a typical dimension of about one micron characterizes the capillary response of the dust. This dimension suggests that brine flow through the dust will be inhibited and that pores or cervices on the metal surface would have to have similar dimension in order to compete successfully for the brine. Also, predicted deliquescent brine volumes, represented as layer thicknesses or droplets on the waste package, are too small to support differences in $\mathrm{O}_{2}$ concentration required to develop the separate anodic and cathodic zones required for initiation of localized corrosion.

5) Once initiated, will localized corrosion penetrate the waste package outer barrier? No. The process of crevice corrosion requires that water be consumed by redox reactions in both the anodic and cathodic regions of the corrosion cell. As corrosion products accumulate in the cell, cathodic limitation will occur from decreased availability of reaction sites where secondary products precipitate, and potentially from decreased availability of oxygen and water if the required transport pathways are restricted. Elevated temperature decreases the aqueous solubility of oxygen, contributing to cathodic limitation. As with many other materials, localized or crevice corrosion penetration of Alloy 22 is best described by a power rate law. Laboratory data clearly show that stifling of crevice corrosion in Alloy 22 occurs. In addition, physical sequestration of brine in the porous corrosion products will inhibit further corrosion. Given the small volumes of brine involved, corrosion products would have to be nearly nonporous not to volumetrically deplete the brine by capillary retention. Finally, the consumption of brine components, especially chloride, by incorporation into corrosion products, may decrease brine corrosivity or lead to brine dryout.

The arguments presented in this paper show that brines formed by deliquescence of tunnel and atmospheric dust compositions are chemically passive with respect to corrosion. Processes that act to modify them on the waste package surface are beneficial with respect to corrosivity. Should corrosive brines form, scale factors related to brine volume will inhibit initiation of localized corrosion. Finally, should corrosion initiate, several processes will act to limit or stifle it before waste package breach.

\footnotetext{
${ }^{1}$ Sandia National Laboratories, Albuquerque, New Mexico, USA.

${ }^{2}$ Lawrence Livermore National Laboratory, Livermore, California, USA.

${ }^{3}$ Bechtel-SAIC Co., Las Vegas, Nevada, USA

${ }^{4}$ U.S. Department of Energy, Office of Repository Development, Las Vegas, Nevada, USA
} 